\title{
Endovascular Recanalization of Symptomatic Nonacute Intracranial Internal Carotid Artery Occlusion: Proposal of a New Angiographic Classification
}

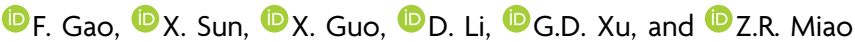

\begin{abstract}
BACKGROUND AND PURPOSE: The optimal treatment for symptomatic nonacute intracranial ICA occlusion is uncertain, and endovascular recanalization remains a technical challenge. Our purpose was to report multicenter clinical results of endovascular recanalization for medically refractory, nonacute, intracranial ICA occlusion and to propose a new angiographic classification to explore which subgroups of patients are most amenable to this treatment.
\end{abstract}

MATERIALS AND METHODS: From January 2015 to December 2019, thirty-six consecutive patients who underwent endovascular recanalization for refractory, nonacute, atherosclerotic intracranial ICA occlusion at 3 stroke centers were analyzed retrospectively. The patients were divided into 3 types according to an angiographic classification. Rates of technical success, periprocedural complications, and any stroke or death within 30 days along with follow-up results were evaluated.

RESULTS: The overall technical success rate was $80.6 \%$ (29/36), and the rate of any stroke or death within 30 days was $16.7 \%$ (6/36). The recanalization success rate gradually decreased from type I to type III in the 3 classification groups $(92.9 \%, 81.3 \%$, and $50 \%$, $P=.038)$, and the opposite was true of the perioperative complication rates $(7.1 \%, 18.8 \%$, and $50 \%, P=.038)$. Type I lesions showed favorable recanalization effects, $92.9 \%$ technical success rates, and $7.1 \%$ perioperative complications.

CONCLUSIONS: Endovascular recanalization for nonacute atherosclerotic intracranial ICA occlusion is technically feasible, especially in patients with type I lesions, and could offer an alternative option for patients with recurrent ischemic symptoms despite aggressive medical therapy. The angiographic classification proposed is conducive to the selection of suitable patients and difficulty in grading.

ABBREVIATIONS: AcomA = anterior communicating artery; ILAO = intracranial large-artery occlusion; IQR = interquartile range; PcomA = posterior communicating artery

ntracranial large-artery occlusion (ILAO) is a common cause of ischemic stroke. ${ }^{1}$ Previous randomized studies have shown an overwhelming benefit of endovascular therapy for selected patients with acute ILAO during the extended 24-hour therapeutic window. ${ }^{2,3}$ A subset of patients with ILAO can tolerate the initial acute occlusion and enter the nonacute phase (including subacute-to-chronic occlusion). Studies have shown that a

Received August 6, 2020; accepted after revision September 19.

From the Departments of Interventional Neuroradiology (F.G., X.S., Z.R.M.), Beijing Tiantan Hospital, and Interventional Neurology (X.G.), Beijing Anzhen Hospital, Capital Medical University, Beijing, China; Department of Neurointervention (D.L.) Dalian Municipal Central Hospital affiliated with Dalian Medical University, Dalian City, Liaoning Province, China; and Department of Neurointervention (G.D.X.), Hebei General Hospital, Shijiazhuang City, Hebei Province, China.

This study was funded by the National Key R\&D Program (2018AAA0102600).

Please address correspondence to Feng Gao, MD, Department of Interventional Neuroradiology, Beijing Tiantan Hospital, Capital Medical University, No.119 South 4th Ring West Rd, Fengtai District, Beijing, China, 100070; e-mail: gaofengletter@sina.com

- Indicates open access to non-subscribers at www.ajnr.org

http://dx.doi.org/10.3174/ajnr.A6928 considerable number of these patients will continue to be at higher risk for subsequent stroke despite aggressive medical therapy. ${ }^{4-6}$ However, the optimal treatment for medically refractory, nonacute ILAO remains unclear. Extracranial-intracranial artery bypass surgery failed to prove benefit in preventing ischemic attacks or stroke. ${ }^{7,8}$ Some small-sample case series studies have reported that endovascular recanalization appeared to be feasible and may be a promising therapeutic option. ${ }^{9,10}$ However, there was heterogeneity of outcomes and perioperative complications for endovascular recanalization, and it is believed that there are differences in the difficulty and risk at different sites of ILAO. ${ }^{10}$

Endovascular recanalization for nonacute occlusion of the intracranial vertebral artery, middle cerebral artery, and basilar artery has been reported in previous studies. ${ }^{11-13}$ However, there are few reports on endovascular recanalization for nonacute intracranial intradural ICA occlusion. ${ }^{14}$ In this study, we retrospectively analyzed 36 consecutive patients with nonacute intracranial intradural ICA occlusion of presumed atherosclerotic etiology who underwent endovascular recanalization at 3 comprehensive 
stroke centers (Department of Interventional Neuroradiology, Beijing Tiantan Hospital; Department of Neurointervention, Dalian Municipal Central Hospital; Department of Neurointervention, Hebei General Hospital); we also propose a new angiographic classification. The aim of the study was to explore the technical feasibility and safety of endovascular recanalization and to provide a reference for the selection of patients and difficulty of grading.

\section{MATERIALS AND METHODS Study Population}

From January 2015 to December 2019, thirty-six consecutive patients with symptomatic, nonacute, intracranial ICA occlusion treated with endovascular recanalization at 3 comprehensive stroke centers were reviewed. Twenty-four patients were men, with an average age of 53.83 years (range, $41-75$ years). In this study, intracranial ICA occlusion was defined as occlusion beyond the ophthalmic artery segment-that is, the intracranial intradural segment including the ophthalmic artery segment and the communicating segment according to the ICA classification proposed by Bouthillier et al. ${ }^{15}$ Nonacute occlusion was defined as occlusion with a time window of $>24$ hours from the onset (TIA or stroke). After intracranial ICA occlusion was diagnosed by CTA or MRA, patients were treated with aggressive medical therapy (dual-antiplatelet therapy plus statins and management of risk factors). ${ }^{16}$ The patients were clinically observed and followed up, and endovascular treatment was considered if they still experienced recurrent TIAs or stroke related to an occluded ICA. Informed consent for endovascular treatment was obtained from all patients. Beijing Tiantan Hospital institutional review board approved this retrospective study, and the requirement for patient informed consent was waived for review of patient records and images.

\section{Inclusion Criteria}

The inclusion criteria were as follows: 1) nonacute intracranial ICA occlusion diagnosed by CTA or MRA and confirmed by DSA; 2) recurrent TIA or stroke related to the occluded ICA despite aggressive medical treatment; 3 ) preoperative CTP revealing hypoperfusion in the occluded ICA territory; ${ }^{17} 4$ ) a preoperative mRS score of equal to or less than three; 5) $>1$ risk factor for atherosclerosis (eg, hypertension, diabetes mellitus, hyperlipidemia, coronary artery disease, and cigarette smoking); and 6) patient refusal to undergo bypass surgery.

\section{Exclusion Criteria}

The exclusion criteria were as follows: 1) clinical, laboratory, or imaging findings not suspicious for atherosclerotic lesions, such as vasculitis, Moyamoya syndrome, arterial dissection; 2) a coexisting cardioembolic source (eg, atrial fibrillation, mitral stenosis, prosthetic valve, Myocardial infarction within 6 weeks, intracardiac clot, ventricular aneurysm, and bacterial endocarditis); 3) a concomitant intracranial aneurysm or any bleeding disorder; 4) large infarct core, defined as an ASPECTS of $<6$ points; and 5) life expectancy of $<1$ year due to other medical conditions.

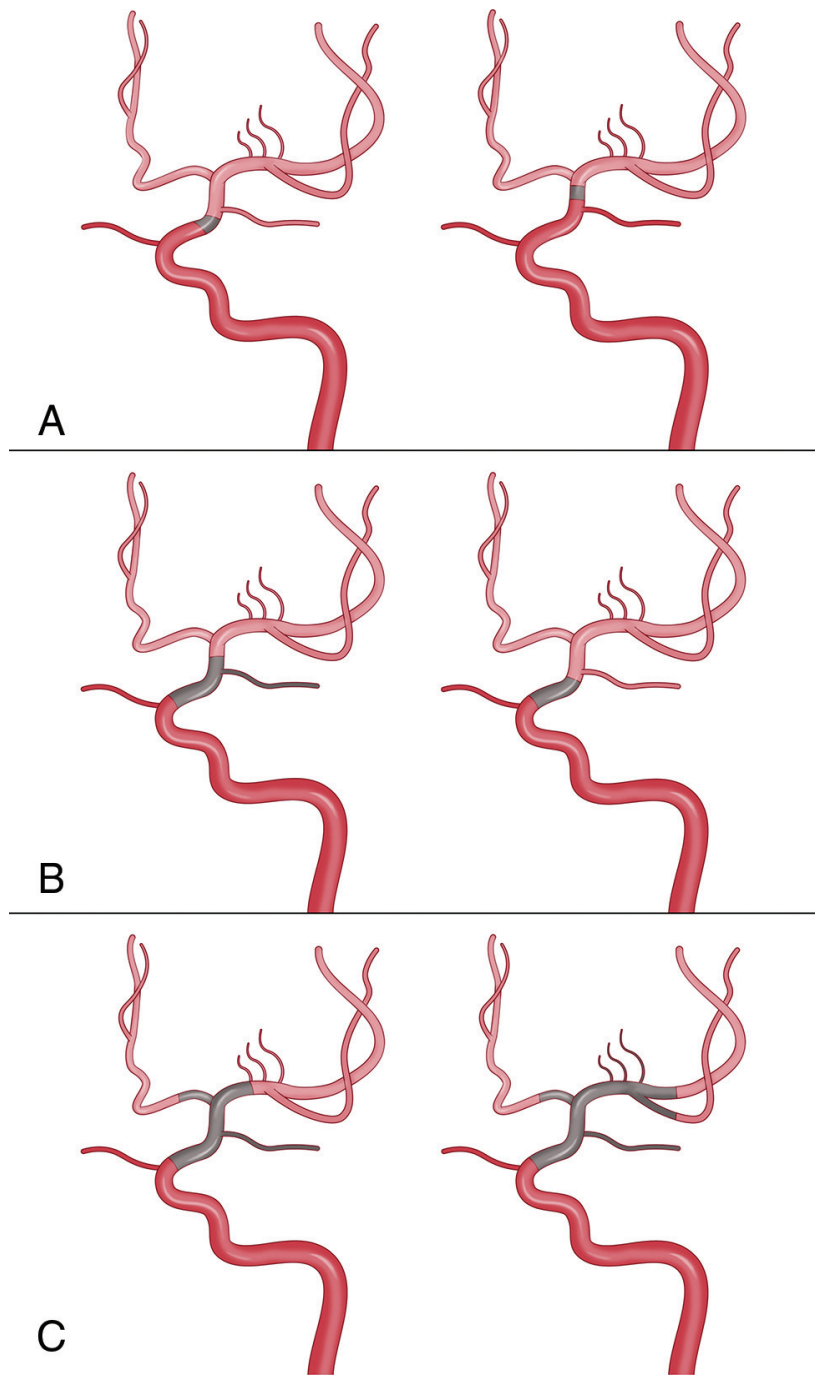

FIG 1. Schematic diagram for the angiographic classification of nonacute intracranial ICA occlusion. A, Type I: the intracranial ICA is occluded, with an occlusion length of $\leq 10 \mathrm{~mm}$ and established collateral filling to the distal intracranial ICA via the PcomA or AcomA. B, Type II: the intracranial ICA is occluded, with an occlusion length of $>10 \mathrm{~mm}$ and established collateral filling to the distal intracranial ICA via the AcomA or PcomA, C, Type III: the intracranial ICA is occluded, with an uncertain occlusion length or involving the middle MCA with no established collateral filling to the distal intracranial ICA via the PcomA or AcomA.

\section{Angiographic Classification of Nonacute Intracranial ICA Occlusion}

Angiographic classification of intracranial ICA occlusion was based on standard cerebral angiography, including the bilateral internal carotid and vertebral arteries with sufficient contrast medium and a prolonged run, which emphasizes opacification of the posterior communicating artery (PcomA), anterior communicating artery (AcomA), or leptomeningeal collateral vessels. The length of occlusion was determined by the distance between proximal occlusion and the reconstruction of distal collateral vessels, which was categorized as $\leq 10$ or $>10 \mathrm{~mm} .{ }^{18}$ On the basis of angiographic characteristics, intracranial ICA occlusion was divided into the following 3 types (Fig 1). 


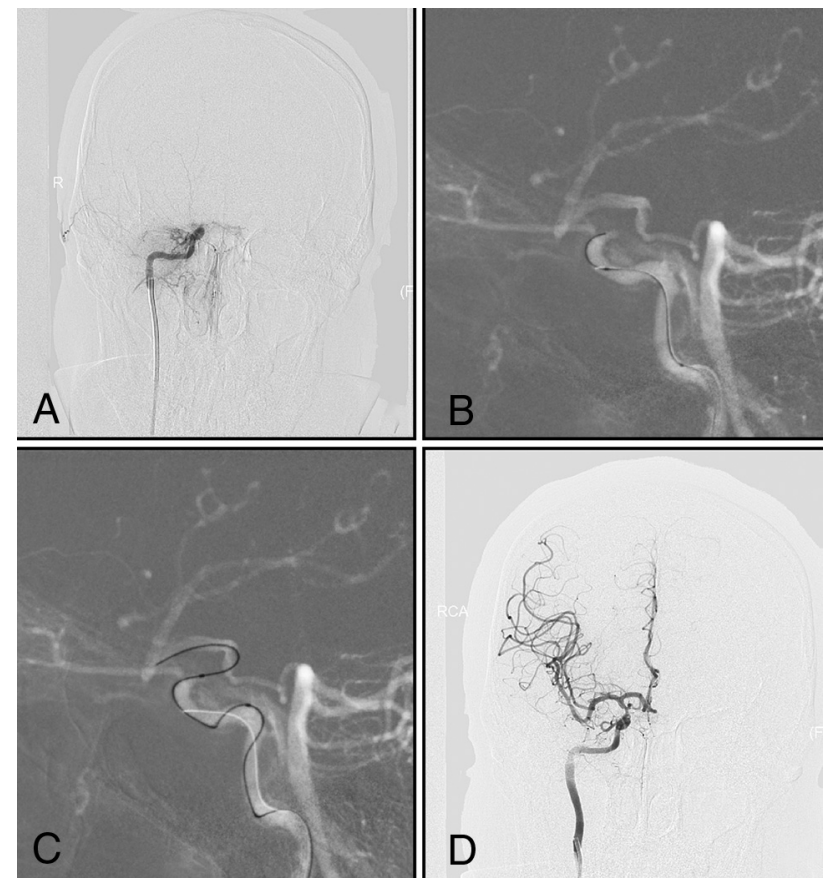

FIG 2. A man with left-sided weakness for 15 days. A, DSA shows that the right intracranial internal carotid artery is occluded, with an occlusion length of $\leq 10 \mathrm{~mm}$ and established collateral filling to the distal intracranial ICA via the PcomA (type I). B and C, Under dual-roadmap guidance, the microwire in combination with a microcatheter passes through the occluded segment. $D$, Successful recanalization.

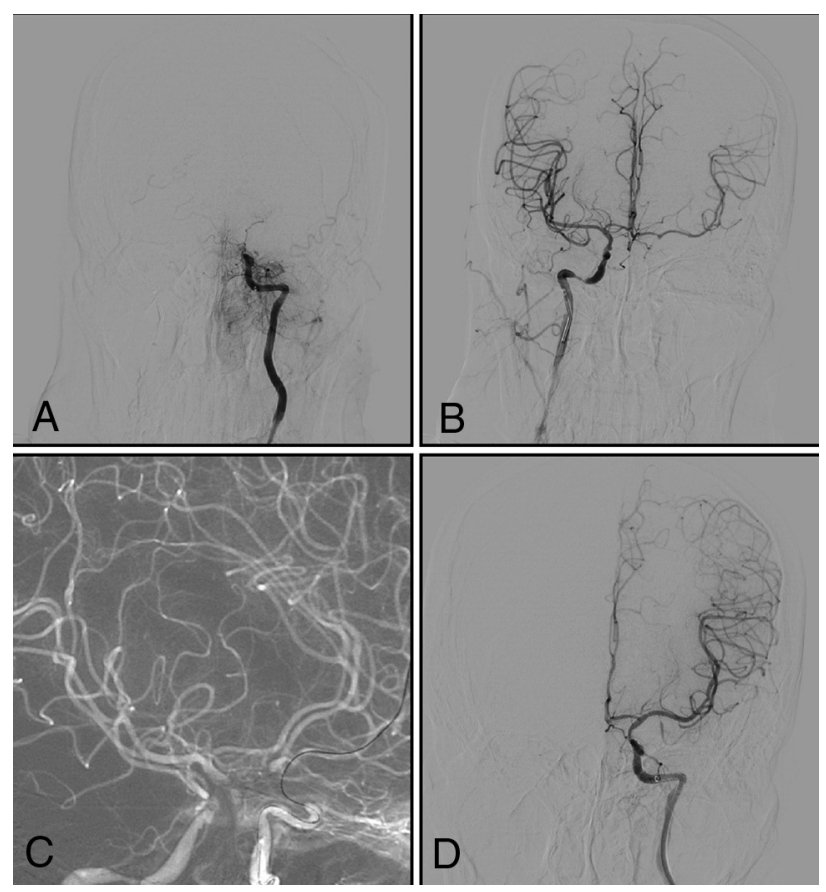

FIG 3. A man with right-sided weakness for 30 days, with increasingly slurred speech for 10 days. $A$ and $B$, DSA shows that the left intracranial internal carotid artery is occluded, with an occlusion length of $>10 \mathrm{~mm}$ and established collateral filling to the distal right intracranial ICA via the AcomA (type II). C, Under dual-roadmap guidance, the microwire, in combination with a microcatheter, passes through the occluded segment. $D$, Successful recanalization.

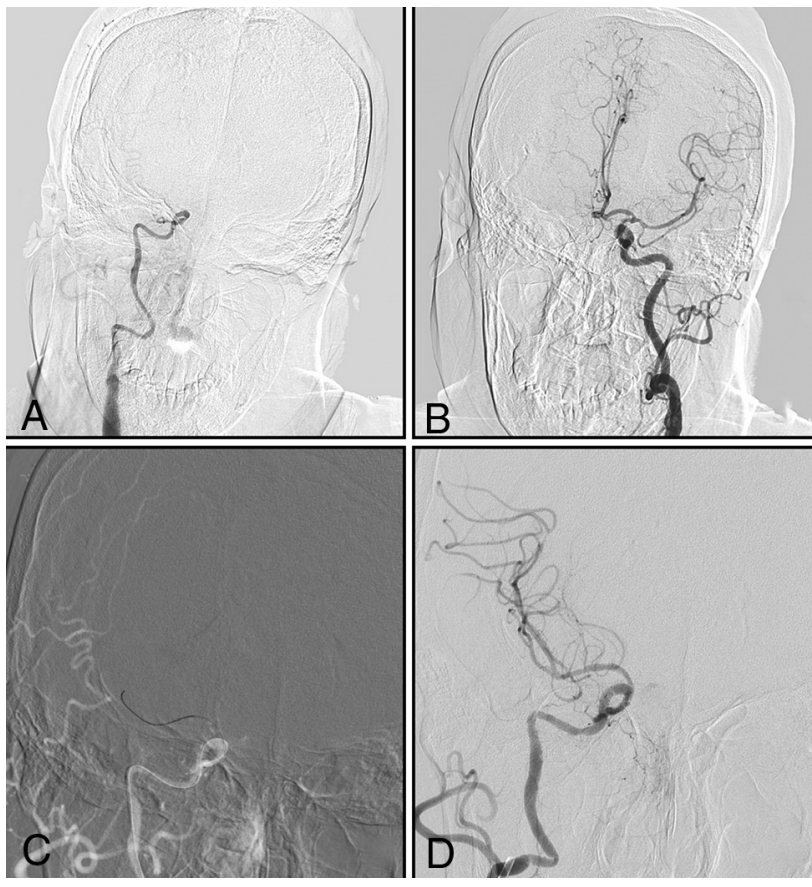

FIG 4. A man with left-sided weakness for 20 days. $A$ and $B, D S A$ shows that the right intracranial internal carotid artery is occluded, with uncertain occlusion length and no established collateral filling to the distal right intracranial ICA via the AcomA or PcomA (type III). $C$, The microwire, in combination with a microcatheter, passes through the occluded segment. $D$, Successful recanalization.

- Type I (Figs $1 A$ and 2): The intracranial ICA is occluded, with an occlusion length of $\leq 10 \mathrm{~mm}$ and established collateral filling to the distal intracranial ICA via the PcomA or AcomA.

- Type II (Figs $1 B$ and 3): The intracranial ICA is occluded, with an occlusion length of $>10 \mathrm{~mm}$ and established collateral filling to the distal intracranial ICA via the AcomA or PcomA.

- Type III (Figs $1 C$ and 4): The intracranial ICA is occluded, with an uncertain occlusion length or involving the MCA and no established collateral filling to the distal intracranial ICA via the PcomA or AcomA.

\section{Endovascular Recanalization Procedure}

All procedures were performed with the patient under general anesthesia. After we placed the sheath introducer, heparin was administered intravenously to keep the activated clotting time between 200 and 300 seconds. A $6 \mathrm{~F}$ guiding catheter was advanced into the cervical segment of the ICA.

For type I and II lesions with a patent PcomA or AcomA, we used dual-roadmap guidance with simultaneous 2-vessel injections to map the course of the occlusion site (Figs 2 and 3). The microwire (Synchro, Stryker Neurovascular; Transend EX 014/ 205 soft tip, Stryker) was used in combination with a microcatheter (Echelon-10, Medtronic; Excelsior SL-10, Stryker) to carefully pass through the occluded segment. If the attempts were repeated and the microwire and microcatheter could not pass the occluded segment and enter the distal true lumen, the procedure was stopped. If the microwire was successfully steered through the occluded segment, then microcatheter injection confirmed the position distal to occlusion in the distal true lumen. 


\begin{tabular}{|c|c|c|c|c|c|}
\hline & Overall $(n=36)$ & Type I $(n=14)$ & Type II $(n=16)$ & Type III $(n=6)$ & $P$ Value \\
\hline Mean age (yr) & $53.83[S D, 10.47]$ & $55.57[S D, 7.98]$ & $52.31[S D, 11.78]$ & $53.83[\mathrm{SD}, 13.01]$ & .708 \\
\hline Men (No.) (\%) & $24(66.7)$ & $10(71.4)$ & $11(68.8)$ & $3(50.0)$ & .722 \\
\hline \multicolumn{6}{|l|}{ Risk factors (No.) (\%) } \\
\hline Diabetes mellitus & $13(36.1)$ & $6(42.9)$ & $4(25.0)$ & $3(50.0)$ & .469 \\
\hline Hypertension & $26(72.2)$ & $11(78.6)$ & $11(68.8)$ & $4(66.7)$ & .789 \\
\hline Hyperlipidemia & $6(16.7)$ & $3(21.4)$ & $3(18.8)$ & 0 & .708 \\
\hline Cardiac disease & $3(8.3)$ & $1(7.1)^{\prime}$ & $2(12.5)$ & 0 & 1 \\
\hline Smoking & $14(38.9)$ & $6(42.9)$ & $7(43.8)$ & $1(16.7)$ & .541 \\
\hline \multicolumn{6}{|l|}{ Qualifying event (No.) (\%) } \\
\hline Recurrent stroke & $33(91.7)$ & $11(78.6)$ & $16(100.0)$ & $6(100.0)$ & .117 \\
\hline Recurrent TIA & $3(8.3)$ & $3(21.4)$ & 0 & 0 & \\
\hline $\begin{array}{l}\text { Imaging occlusion-to-recanalization time } \\
\text { (median) (IQR) (day) }\end{array}$ & $45.00(30.50-68.50)$ & $52.50(32.00-90.00)$ & $41.00(30.00-60.00)$ & $54.50(19.50-90.00)$ & .387 \\
\hline $\begin{array}{l}\text { Last symptom-to-recanalization time } \\
\text { (median) (IQR) (day) }\end{array}$ & $14.00(10.00-17.75)$ & $13.50(10.00-20.25)$ & $13.00(10.00-17.75)$ & $14.50(13.25-17.00)$ & .72 \\
\hline Preoperative NIHSS score (median) (IQR) & $2.00(2.00-4.00)$ & $2.00(1.00-4.00)$ & $2.00(2.00-4.00)$ & $2.00(1.75-4.00)$ & .266 \\
\hline Preoperative mRS score (median) (IQR) & $2.00(1.00-3.00)$ & $1.00(1.00-2.00)$ & $2.00(1.00-2.00)$ & $2.00(1.00-3.00)$ & .317 \\
\hline
\end{tabular}

Subsequently, an exchange-length microwire (Transend ES 014/ 300 Floppy; Stryker) was placed in the appropriate anchoring position, and the microcatheter was removed. A 2- to $2.5-\mathrm{mm}$ Gateway angioplasty balloon (Stryker) was advanced to predilate the lesion. On the basis of measurement of the proximal and distal diameters as well as the length of the occluded segment after balloon dilation, a self-expandable stent (Wingspan stent, Stryker; Neuroform EZ, Stryker; or Enterprise, Codman \& Shurtleff) was introduced and deployed according to the operator's preference.

Postoperative angiography was performed to confirm the patency. Successful revascularization was defined as a modified TICI grade 3 antegrade flow and residual stenosis of $\leq 50 \%$. Brain CT immediately after the operation was performed to rule out intracranial hemorrhage. Then, all patients were typically monitored in Neurocritical Care Units for 24 hours postprocedure with a goal of systolic blood pressure within $20 \mathrm{mmHg}$ Torr of the patient's baseline blood pressure to reduce the risk of reperfusion hemorrhage. $^{19}$

Combination treatment with oral aspirin (100 mg) and clopidogrel $(75 \mathrm{mg})$ was started at least 5 days before the endovascular procedure. Thromboelastography was used to evaluate platelet reactivity. ${ }^{20}$ No aspirin resistance was observed, and the 6 patients who showed clopidogrel resistance were treated with ticagrelor, $90 \mathrm{mg}$ twice a day. Dual-antiplatelet therapy was maintained for 6 months, with life-long aspirin or clopidogrel monotherapy maintained thereafter.

\section{Data Collection and Follow-Up}

Cases were identified through a search of prospectively acquired endovascular databases of 3 comprehensive stroke centers. We collected the following baseline and treatment variables: demographic, clinical, procedural, imaging, and follow-up data. All image assessments were performed by 2 independent neuroradiologists, and discrepancies were resolved by consensus. Restenosis was defined as $>50 \%$ stenosis within the implanted stent and $>20 \%$ absolute luminal loss on CTA or DSA. ${ }^{21}$

\section{Statistical Analysis}

All normally distributed continuous quantitative variables were expressed as means [SDs]; nonnormally distributed continuous variables, as median and interquartile range; and categoric variables, as proportions. Comparisons between groups were performed using the Student $t$ test or the approximate $\chi^{2}$ test when the variances of comparison between groups were quite different. The comparison among the 3 groups was performed using the $\chi^{2}$ test for trend. Differences were considered statistically significant with $P \leq .05$. All statistical analyses were performed with SPSS 25.0 (IBM).

\section{RESULTS}

\section{Baseline Characteristics}

All 36 patients underwent endovascular recanalization for symptomatic, nonacute, intracranial ICA occlusion. The median time from last symptom onset to endovascular treatment was 14 days (interquartile range $[\mathrm{IQR}]=10.00-17.75$ days). These patients were classified into 3 types according to the angiographic classification. There was no significant difference in the patients' demographic characteristics, risk factors, or clinical characteristics. See Table 1 for the detailed baseline information.

\section{Perioperative Outcome}

The overall technical success rate was $80.6 \%$ (29/36). The perioperative complication rate was $19.4 \%(7 / 36)$, and the overall rate of stroke or death within 30 days was $16.7 \%(6 / 36)$. The recanalization success rate gradually decreased from type I to type III in the 3 classification groups $(92.9 \%, 81.3 \%$, and $50 \% ; P=.038)$, and the opposite was true of the overall perioperative complication rates (7.1\%, $18.8 \%$, and $50 \%, P=.038)$. Table 2 presents the detailed clinical and angiographic outcomes. Two patients experienced vessel perforation with subarachnoid hemorrhage during attempts to traverse the occluded segment with a microwire. After coiling, 1 patient presented with a mild headache, which was relieved 2 days later. The other patient had new neurologic symptoms (NIHSS 5). Two patients had reperfusion hemorrhage 


\begin{tabular}{|c|c|c|c|c|c|}
\hline & Overall $(n=36)$ & Type I $(n=14)$ & Type II $(n=16)$ & Type III $(n=6)$ & $P$ Value \\
\hline Technical success (No.) (\%) & $29(80.6)$ & $13(92.9)$ & $13(81.3)$ & $3(50.00)$ & .038 \\
\hline Periprocedural complication (No.) (\%) & 7 (19.4) & $1(7.1)$ & $3(18.8)$ & $3(50.00)$ & .038 \\
\hline Perforation & $2(5.6)^{\prime}$ & 0 & 0 & $2(33.3)$ & .027 \\
\hline Dissection & $2(5.6)$ & 0 & $1(6.25)$ & $1(16.7)$ & .145 \\
\hline Thrombosis & $1(2.8)$ & $1(7.1)$ & 0 & 0 & .274 \\
\hline Reperfusion hemorrhage & $2(5.6)$ & 0 & $2(12.5)$ & 0 & .654 \\
\hline Stroke within 30 days (No.) (\%) & $6(16.7)$ & $1(7.1)$ & $2(12.5)$ & $3(50.00)$ & .039 \\
\hline Ischemic stroke & $2(5.6)$ & $1(7.1)$ & 0 & $1(16.7)$ & .654 \\
\hline Hemorrhagic stroke & $4(11.1)$ & 0 & $2(12.50)$ & $2(33.3)$ & .034 \\
\hline Death within 30 days (No.) (\%) & $2(5.6)$ & 0 & $2(12.5)$ & 0 & .654 \\
\hline mRS score at 90 days (median) (IQR) & $1.00(1.00-2.00)$ & $1.00(0.00-2.00)$ & $1.00(1.00-2.00)$ & $1.00(1.00-2.00)$ & .218 \\
\hline Clinical follow-up (median) (IQR) (mo) & $12.00(6.00-24.00)$ & $9.00(6.00-14.25)$ & $24.00(7.50-34.50)$ & $9.00(8.00-9.00)$ & .267 \\
\hline Imaging follow-up (median) (IQR) (mo) & $12.00(3.00-12.00)$ & $6.00(3.00-12.00)$ & $12.00(3.00-12.00)$ & $24.00(6.00-24.00)$ & .28 \\
\hline Stroke and death beyond 30 days (No.) (\%) & $2 / 27(7.40)$ & $1 / 12(8.33)$ & $1 / 12(8.33)$ & $0 / 3$ & 1 \\
\hline Restenosis (No.) (\%) & $4 / 26(15.38)$ & $1 / 11(9.09)$ & $3 / 12(25.00)$ & $0 / 3$ & .757 \\
\hline
\end{tabular}

3 and 4 hours after successful recanalization; their symptoms deteriorated rapidly, and they died. Two patients underwent vascular dissection, and the operation was terminated because the guidewire could not pass through the occlusion to the distal vascular true lumen. One patient had mild ischemic stroke (NIHSS 3) after the operation, and the other one was asymptomatic. One patient experienced left-limb weakness (NIHSS 4) five days after successful recanalization, and transcranial Doppler showed patency of the treated right ICA.

\section{Follow-Up Outcome}

The median clinical follow-up period was 12 months $(\mathrm{IQR}=$ 6.00-24.00). Stroke or death occurred at a rate of 7.4\% (2/27) during follow-up. One patient each experienced ipsilateral ischemic stroke at 3 and 6 months after the operation, and CTA revealed in-stent restenosis; the symptoms improved after drug and rehabilitation treatment ( $\mathrm{mRS} 1$ ). The median imaging follow-up period was 12 months (IQR $=3.00-12.00$ months). Four patients (15.4\%, 4/26) developed in-stent restenosis: Two were symptomatic, and the other 2 were asymptomatic.

\section{DISCUSSION}

In previous studies of intracranial ICA stenosis or occlusive diseases, the intracranial ICA usually refers to the C2-C7 segment (beyond the petrous segment). ${ }^{22,23}$ When the primary occlusion occurs at the proximal-to-ophthalmic artery orifice (C2-C5 segment), due to the lack of an ophthalmic artery outflow tract, it is often accompanied by proximal blood flow stagnation or secondary thrombus extension involving the extracranial cervical ICA. In this case, it is very difficult to identify the primary occlusion point using angiography alone, and the occlusion is usually ambiguously referred to as an ICA occlusion or cervical ICA occlusion. Previous research by Lee et $\mathrm{al}^{24}$ suggested that the difficulty and risk of endovascular recanalization for ICA occlusion involving the intradural segment were increased due to the difference in the anatomic structures between the intradural and epidural segments.

In this study, we report, for the first time, the multicenter preliminary results of endovascular recanalization for nonacute, intracranial, intradural ICA occlusion. The results show that the overall recanalization rate was $80.6 \%$ and the perioperative complication rate was $19.4 \%$. Patients with type I occlusions had higher revascularization rates than those with type II or III occlusions $(92.9 \%, 81.3 \%$, and $50 \%$, respectively), and the opposite was true of overall perioperative complication rates $(7.1 \%, 18.8 \%$, and $50 \%$, respectively), which indicated that different patient selection may lead to different recanalization outcomes.

When intracranial ICA occlusion occurs, the distal collateral pathway mainly originates from the PcomA, AcomA, or leptomeningeal collateral vessels. The length of occlusion judged is mainly based on the distance between the proximal occlusion and reconstruction of distal collateral vessels, which may be longer than the true length of underlying atherosclerotic lesions. ${ }^{25}$ In our study, the occlusion length of type I lesions was $<10 \mathrm{~mm}$, which was equivalent to the length of type B stenosis according to the classification of Mori et al. ${ }^{18}$ In types II and III, when the primary occlusion was located in the ophthalmic artery segment, the occlusion may extend beyond the PcomA due to hypoplasia or absence of a PcomA.

Good reconstruction of distal collateral vessels is a favorable factor for endovascular recanalization because it increases the visibility of distal vessels. ${ }^{26}$ Given the opening of the PcomA or AcomA, for type I and type II lesions, the dual-roadmap technique can be used to inject contrast into the proximal and distal vessels through the bilateral ICA or the ICA combined with the vertebral artery at the same time so that these vessels can be visualized simultaneously in roadmap mode. This procedure can extrapolate the course of the occluded site, define the length of the occlusion, and provide a "landing point" and distal vascular navigation for the guidewire to pass through smoothly. In the current series, type I lesions showed a high recanalization rate (92.9\%) and a low incidence of perioperative complications (7.1\%) because of the relatively short occlusion $(\leq 10 \mathrm{~mm})$ and good reconstruction of distal collateral vessels from the PcomA or AcomA, which may be the best candidates for endovascular recanalization. Type II lesions were more difficult to recanalize than type I lesions because of their longer occlusion length $(>10 \mathrm{~mm})$, but due to collateral reconstruction from the AcomA, occlusions were still relatively limited between the origin of the ophthalmic artery and the distal bifurcation of the ICA. Although there was an acceptable success rate of recanalization (81.3\%), it was accompanied by a high perioperative complication rate (18.8\%). Therefore, for patients of type II lesion, endovascular 
therapy, as an alternative treatment for medically refractory patients, needs to be comprehensively weigh the risks and benefits in this group.

For type III lesions, this study showed a low recanalization rate $(50 \%)$ and a high incidence of perioperative complications (50\%). Because of involvement or absence of the AcomA or PcomA, the uncertainty of occlusion length and course significantly increased the operational risk of endovascular recanalization. The incidence of operation-related complications such as vascular perforation was significantly higher in type III, which may suggest that endovascular recanalization should be performed with caution in these patients. In fact, in type III, the distal collateral pathway mainly comes from the leptomeningeal anastomosis between the middle and anterior cerebral arteries or the posterior cerebral arteries, and angiography may show late retrograde opacification of the distal MCA M1 trunk or M2-3 branches. According to different distal collateral reconstructions, type III can be divided into subtypes a and b: In subtype a, retrograde filling of the distal collateral can be seen in the distal MCA M1 trunk; in subtype b, retrograde filling of the distal collateral can be seen only in the M2-3 branches. Because of the small sample size, we did not have separate statistics. Further study with a larger case number is warranted.

Intracranial hemorrhagic complication, including subarachnoid hemorrhage and parenchymal hematoma, can be caused by microwire perforation, reperfusion injury, or hemorrhagic transformation. The use of soft-tipped hydrophilic-coated microwires and dual-roadmap guidance by experienced operators can help reduce the incidence of operation-related complications such as guidewire perforation. Reperfusion hemorrhage is still a potentially devastating complication after recanalization. The frequency of reperfusion hemorrhage has been reported to range from $0.3 \%$ to $1.2 \%$ following carotid endarterectomy and $0.67 \%-$ $2.3 \%$ following carotid stent placement in different series, ${ }^{27,28}$ though there are scant data on the risk following endovascular recanalization for nonacute intracranial occlusion. ${ }^{9,12}$ In the present study, we report that the incidence of reperfusion hemorrhage was 5\% (2/40) after endovascular recanalization for nonacute, intracranial, intradural ICA occlusion. The mechanism of reperfusion hemorrhage may be related to cerebral autoregulation and blood-brain barrier damage caused by long-term chronic ischemia, and it can be reduced by intensive treatment of perioperative hypertension. ${ }^{28}$

Another concern is thromboembolic complications. Secondary thrombosis may occur proximal or distal to the ICA occlusion, which may displace and cause distal embolism during endovascular recanalization. In this group, no thromboembolism occurred during the operation, considering that it was related to the degree of organization of secondary thrombosis. The stent was placed after balloon dilation to scaffold the occlusion; perioperative, dualantiplatelet therapy and intraoperative heparinization were helpful in reducing the occurrence of thromboembolic events. It has been reported in some cases that proximal balloon occlusion and a flowreversal device were used to prevent distal embolization. ${ }^{23}$

The clinical symptoms of the patients in this group were relatively mild, which may be mainly related to the following factors: 1) Some patients with large-core infarction and severe clinical symptoms were excluded; 2) in some patients with recurrent stroke, the pattern of infarction was watershed infarction with mild clinical symptoms; and 3) the median time from last ischemic symptom onset to endovascular treatment was 14 days (IQR = 10.00-17.75), and some patients recovered somewhat before the operation.

Our study has some limitations. First, this study was a retrospective study with a modest sample size, and further prospective studies are needed to confirm the results. Second, the lack of long-term follow-up imaging data in some patients may limit the evaluation of the overall restenosis rate. Finally, this study lacked a medically managed control arm, and it remains unknown whether endovascular recanalization compares favorably with the best medical therapies. However, before a controlled study, it is important to carefully explore which subgroups of patients are most amenable to endovascular treatment.

\section{CONCLUSIONS}

Endovascular recanalization for nonacute atherosclerotic, intracranial, intradural ICA occlusion is technically feasible, especially in patients with type I, and could offer an alternative option for patients with recurrent ischemic symptoms despite aggressive medical therapy. The angiographic classification proposed is conducive to the selection of suitable patients and difficulty in grading. Endovascular recanalization of nonacute intracranial ICA occlusion is still a high-risk procedure; therefore, selecting the subgroup of patients who could benefit from this treatment is critical.

\section{REFERENCES}

1. Smith WS, Lev MH, English JD, et al. Significance of large vessel intracranial occlusion causing acute ischemic stroke and TIA. Stroke 2009;40:3834-40 CrossRef Medline

2. Berkhemer OA, Majoie CB, Dippel DW, MR CLEAN Investigators. Endovascular therapy for ischemic stroke. $N$ Engl $J$ Med 2015;372:2363 CrossRef Medline

3. Nogueira RG, Jadhav AP, Haussen DC, et al; DAWN Trial Investigators. Thrombectomy $\mathbf{6}$ to $\mathbf{2 4}$ hours after stroke with a mismatch between deficit and infarct. $N$ Engl J Med 2018;378:11-21 CrossRef Medline

4. Yamauchi H, Higashi T, Kagawa S, et al. Chronic hemodynamic compromise and cerebral ischemic events in asymptomatic or remote symptomatic large-artery intracranial occlusive disease. AJNR Am J Neuroradiol 2013;34:1704-10 CrossRef Medline

5. Kuroda S, Houkin K, Kamiyama H, et al. Long-term prognosis of medically treated patients with internal carotid or middle cerebral artery occlusion: can acetazolamide test predict it? Stroke 2001;32:2110-16 CrossRef Medline

6. Yamauchi H, Fukuyama H, Nagahama Y, et al. Evidence of misery perfusion and risk for recurrent stroke in major cerebral arterial occlusive diseases from PET. J Neurol Neurosurg Psychiatry 1996;61:18-25 CrossRef Medline

7. EC/IC Bypass Study Group. Failure of extracranial-intracranial arterial bypass to reduce the risk of ischemic stroke: results of an international randomized trial. N Engl J Med 1985;313:1191-1200 CrossRef Medline

8. Powers WJ, Clarke WR, Grubb RL Jr, et al; COSS Investigators. Extracranial-intracranial bypass surgery for stroke prevention in hemodynamic cerebral ischemia: the Carotid Occlusion Surgery Study randomized trial. JAMA 2011;306:1983-92 CrossRef Medline 
9. Aghaebrahim A, Jovin T, Jadhav AP, et al. Endovascular recanalization of complete subacute to chronic atherosclerotic occlusions of intracranial arteries. J Neurointerv Surg 2014;6:645-48 CrossRef Medline

10. Yao YD, Liu AF, Qiu HC, et al. Outcomes of late endovascular recanalization for symptomatic non-acute atherosclerotic intracranial large artery occlusion. Clin Neurol Neurosurg 2019;187:105567 CrossRef Medline

11. Gao P, Wang Y, Ma Y, et al. Endovascular recanalization for chronic symptomatic intracranial vertebral artery total occlusion: experience of a single center and review of literature. J Neuroradiol 2018;45:295-304 CrossRef Medline

12. Zheng M, Song Y, Zhang J, et al. Endovascular recanalization of non-acute symptomatic middle cerebral artery total occlusion and its short-term outcomes. Front Neurol 2019;10:484 CrossRef Medline

13. Dashti SR, Park MS, Stiefel MF, et al. Endovascular recanalization of the subacute to chronically occluded basilar artery: initial experience and technical considerations. Neurosurgery 2010;66:825-31; discussion 831-32 CrossRef Medline

14. Wang $\mathrm{X}$, Wang Z, Ji Y, et al. Enterprise stent in recanalizing nonacute atherosclerotic intracranial internal carotid artery occlusion. Clin Neurol Neurosurg 2017;162:47-52 CrossRef Medline

15. Bouthillier A, van Loveren HR, Keller JT. Segments of the internal carotid artery: a new classification. Neurosurgery 1996;38:425-42; discussion 432-33 CrossRef Medline

16. Chimowitz MI, Lynn MJ, Derdeyn CP, et al; SAMMPRIS Trial Investigators. Stenting versus aggressive medical therapy for intracranial arterial stenosis. N Engl J Med 2011;365:993-1003 CrossRef Medline

17. Murphy BD, Fox AJ, Lee $\mathrm{DH}$, et al. Identification of penumbra and infarct in acute ischemic stroke using computed tomography perfusion-derived blood flow and blood volume measurements. Stroke 2006;37:1771-77 CrossRef Medline

18. Mori T, Fukuoka M, Kazita K, et al. Follow-up study after intracranial percutaneous transluminal cerebral balloon angioplasty. AJNR Am J Neuroradiol 2000;6(Suppl 1):243-49 CrossRef Medline
19. Alexander MJ, Zauner A, Chaloupka JC, et al; WEAVE Trial Sites and Interventionalists. WEAVE trial: final results in 152 on-label patients. Stroke 2019;50:889-94 CrossRef Medline

20. Sun X, Tong X, Lo WT, et al. Risk factors of subacute thrombosis after intracranial stenting for symptomatic intracranial arterial stenosis. Stroke 2017;48:784-86 CrossRef Medline

21. Levy EI, Turk AS, Albuquerque FC, et al. Wingspan in-stent restenosis and thrombosis: incidence, clinical presentation, and management. Neurosurgery 2007;61:644-50; discussion 650-51 CrossRef Medline

22. Ko JK, Choi $\mathrm{CH}$, Cha $\mathrm{SH}$, et al. Percutaneous transluminal angioplasty and stenting for severe stenosis of the intracranial extradural internal carotid artery causing transient ischemic attack or minor stroke. Interv Neuroradiol 2015;21:511-19 CrossRef Medline

23. Komiyama M, Yoshimura M, Honnda Y, et al. Percutaneous angioplasty of a chronic total occlusion of the intracranial internal carotid artery: case report. Surg Neurol 2006;66:513-18; discussion 518 CrossRef Medline

24. Lee CW, Lin YH, Liu HM, et al. Predicting procedure successful rate and 1-year patency after endovascular recanalization for chronic carotid artery occlusion by CT angiography. Int J Cardiol 2016;221:772-76 CrossRef Medline

25. He Y, Wang $\mathrm{Z}, \mathrm{Li} \mathrm{T}$, et al. Preliminary findings of recanalization and stenting for symptomatic vertebrobasilar artery occlusion lasting more than $24 \mathrm{~h}$ : a retrospective analysis of 21 cases. Eur J Radiol 2013;82:1481-86 CrossRef Medline

26. Stone GW, Reifart NJ, Moussa I, et al. Percutaneous recanalization of chronically occluded coronary arteries: a consensus document: Part II. Circulation 2005;112:2530-37 CrossRef Medline

27. Ouriel K, Shortell CK, Illig KA, et al. Intracerebral hemorrhage after carotid endarterectomy: incidence, contribution to neurologic morbidity, and predictive factors. J Vasc Surg 1999;29:82-87; discussion 87-89 CrossRef Medline

28. Abou-Chebl A, Yadav JS, Reginelli JP, et al. Intracranial hemorrhage and hyperperfusion syndrome following carotid artery stenting: risk factors, prevention, and treatment. $\mathrm{A}$ Am Coll Cardiol 2004;43:1596-1601 CrossRef Medline 